\title{
MYH9 overexpression correlates with clinicopathological parameters and poor prognosis of epithelial ovarian cancer
}

\author{
LONGYANG LIU $^{1 *}$, JUANJUAN YI $^{2 *}$, XIAOJIE DENG $^{3}$, JIANHUAN YUAN $^{4}$, \\ BEIXIAN ZHOU ${ }^{3}$, ZHONGQIU LIN ${ }^{5}$ and ZHAOYANG ZENG ${ }^{1}$
}

\begin{abstract}
${ }^{1}$ Department of Gynecology, Integrated Hospital of Traditional Chinese Medicine, Southern Medical University, Guangzhou, Guangdong 510315; ${ }^{2}$ Department of Dermatovenereology, Foshan Maternal and Child Health Hospital, Foshan, Guangdong 528000; ${ }^{3}$ Department of Oncology, Integrated Hospital of Traditional Chinese Medicine, Southern Medical University, Guangzhou, Guangdong 510315; ${ }^{4}$ Department of Gynecology,

The First People's Hospital of Huizhou City, Huizhou, Guangdong 516000; ${ }^{5}$ Department of Gynecology Oncology, The Memorial Hospital of Sun Yat-sen University, Guangzhou, Guangdong 510000, P.R. China
\end{abstract}

Received July 9, 2018; Accepted April 2, 2019

DOI: $10.3892 / \mathrm{ol} .2019 .10406$

\begin{abstract}
The aim of the present study was to investigate the expression of myosin 9 (MYH9) in epithelial ovarian cancer and to explore its correlation with the clinicopathological parameters and prognosis of epithelial ovarian cancer (EOC). A total of 265 cases of paraffin-embedded ovarian cancer tissues and 41 paratumor tissues which had been pathologically confirmed at the Memorial Hospital of Sun Yat-sen University from 2009 to 2017 were included in the present study. MYH9 expression was investigated with immunohistochemistry using a polyclonal antibody specific for MYH9. MYH9 expression is associated with disease progression free and overall survival in epithelial ovarian cancer patients; and the expression of MYH9 is associated with International Federation of Gynecology and Obstetrics stage, lymph node metastasis, intraperitoneal metastasis, survival status (at last follow-up), intraperitoneal recurrence, residual tumor size and ascites with tumor cells. Moreover, in a multivariate model MYH9 overexpression was an independent predictor of poor survival in epithelial ovarian
\end{abstract}

Correspondence to: Professor Zhongqiu Lin, Department of Gynecology Oncology, The Memorial Hospital of Sun Yat-sen University, 102 Yanjiang Street, Guangzhou, Guangdong 510000, P.R. China

E-mail: linzhongqiu@hotmail.com

Professor Zhaoyang Zeng, Department of Gynecology, Integrated Hospital of Traditional Chinese Medicine, Southern Medical University, 13 Shiliugang Street, Guangzhou, Guangdong 510315, P.R. China

E-mail: zengzhaoyang30@163.com

${ }^{*}$ Contributed equally

Key words: MYH9, epithelial ovarian cancer, clinicopathological, prognostic cancer. MYH9 may be a candidate that plays a oncogenic role in epithelial ovarian cancer. MYH9 is a useful independent prognostic marker in epithelial ovarian cancer, and it may provide a candidate target therapy treatment of ovarian cancer in the future.

\section{Introduction}

Ovarian cancer is one of the most common female low genital malignant cancers. A total of $\sim 238,700$ women are annually diagnosed with this disease all over the world and $\sim 151,900$ associated fatalities (1). In addition, epithelial ovarian cancer (EOC) accounts for $90 \%$ of all types of ovarian cancer. Most of EOC is diagnosed at an advanced stage [the International Federation of Gynecology and Obstetrics (FIGO) III or IV stages] because of the lack of specific symptoms and the absence of effective early diagnostic methods, which leads to a poor prognosis $(2,3)$. Recently serum biomarkers such as CA125 and HE4 have been used to monitor the progress and prognosis of the EOC, and also to detect the recurrence of disease after operation or chemotherapy $(4,5)$. However, these biomarkers are neither particularly specific nor extremely sensitive for predicting cancer metastasis, recurrence and prognosis. Therefore, further studies to find new biomarkers and to provide targeted therapy are very important.

The myosin 9 (MYH9) gene encodes the heavy chain of non-muscle myosin of class II, isoform A (also called NM IIA). The MYH9 gene is localized on chromosome 22q12.3, spanning $>106 \mathrm{kbp}$ and composed of 41 exons (6). Several studies suggested that MYH9 plays a different role in various types of cancers. Many studies propose that NM IIA expression or its functions in neoplastic cells promote the progression of various types of cancers (7-14). However, the studies that obtained the strongest evidence of a driving role of MYH9 alterations in oncogenesis found that this gene acts as a tumor suppressor (15-17). In addition, it was demonstrated that silencing of MYH9 induced metastatic squamous cell carcinoma (SCC) in the skin and head and neck with median 
latencies of 3 to 7 months, and ablation of MYH9 also led to development of skin SCC. Moreover, investigation of mouse and human keratinocytes demonstrated that NM IIA deficiency induced defective activation of the p53 protein upon DNA damage, as a result of impaired p53 stability and nuclear localization, and the authors found that $24-31 \%$ of human skin and head and neck SCCs are characterized by no or very weak NM IIA expression. In addition, analysis of data from The Cancer Genome Atlas indicated that low MYH9 mRNA expression is associated with poor survival in patients with head and neck SCC, therefore also supporting a role for MYH9 as a tumor suppressor in humans. Notably, in the tongue SCC (18) and in human invasive lobular breast carcinoma (19), MYH9 acts as a tumor suppressor.

However, to the best of our knowledge there have been no research about the role of MYH9 in ovarian cancer. Therefore, in the preset study the aim was to study the role of MYH9 expression in ovarian cancer and its clinicopathological and prognostic correlations.

\section{Materials and methods}

Tissue specimens and patient samples. A total of 265 paraffin-embedded ovarian cancer tissues (saved at Department of Pathology in the Memorial Hospital of Sun Yat-sen University; the women were aged between 18 and 89 years old) and 41 paratumor ovarian tissues (saved at the Department of Pathology in the Memorial Hospital of Sun Yat-sen University; the women were aged between 51 and 72 years old) from March 2009 to December 2017 which had been pathologically confirmed at the Memorial Hospital of Sun Yat-sen University were included in this study, and all of the paraffin-embedded tissues were cut into $4 \mu \mathrm{m}$-thick tissues and made to paraffin section. Survival was calculated from the operation date until 14 April 2018 when any remaining survivors were censored. This trial obtained approval from the Memorial Hospital of Sun Yat-sen University Ethics Committee. All controls and patients (or relatives of patients who already died) provided written informed consent.

Immunohistochemistry. The MYH9 expression levels in the human EOC tissues were detected by immunohistochemical analysis. Briefly, the samples were fixed in $4 \%$ formaldehyde for $12 \mathrm{~h}$ subsequently $4 \mu \mathrm{m}$-thick paraffin-embedded sections (saved at $-20^{\circ} \mathrm{C}$ ) were incubated at $65^{\circ} \mathrm{C}$ for $2 \mathrm{~h}$, deparaffinized with xylene, rehydrated and microwaved in antigen retrieval buffer. Next, high tension was used for antigen retrieval and the specimens were treated with $3 \%$ hydrogen peroxide in methanol to quench endogenous peroxidase activity, followed by incubation with $1 \%$ bovine serum albumin (OriGene Technologies, Inc.) to block non-specific binding (room temperature for $15 \mathrm{~min}$ ), and incubation with anti-rabbit MYH9 polyclonal antibody (1:100; cat. no. 11128-1-AP; Proteintech, Inc.) at $4^{\circ} \mathrm{C}$ overnight. After washing, the tissue sections were treated with secondary antibody (goat anti-mouse/rabbit IgG, cat no: SP-9000,; $50 \mathrm{ul}$ for each section; OriGene Technologies, Inc,) for $2 \mathrm{~h}$ at room temperature, then incubated with streptavidin horseradish peroxidase complex (OriGene Technologies, Inc.) for $15 \mathrm{~min}$ at room temperature, immersed in 3-amino-9-ethyl carbazole. The sections were then counterstained with $10 \%$ Mayer's hematoxylin (2 min at room temperature), dehydrated and mounted in Crystal Mount. A total of two researchers evaluated the degree of immunostaining of each formalin-fixed, paraffin-embedded section with light microscope (x200 or $x 400$; Olympus). The score was due to both the proportion of positively stained tumor cells and the intensity of staining. The percentage of cancer cells was scored as follows: Sections with $<10 \%$ positive cancer cells were scored as $0 ; 10-50 \%$ positive cancer cells were scored as $1 ; 50-75 \%$ positive cancer cells were scored as 2 ; and $>75 \%$ positive cancer cells were scored as, 3 . Meanwhile, the tissues were sorted into four grades based on staining intensity, as follows: 0 indicated no staining; 1 indicated weak staining (light yellow); 2 moderate staining (yellow brown); and 3 strong staining (brown). The staining index (0-9) was calculated as the product of the proportion of positive cells multiplied by the staining intensity score. The best cutoff value was defined as follows: A staining score of $\geq 6$ was considered to have high MYH9 expression and a staining score of $\leq 4$ indicated low MYH9 expression (20).

Statistical analysis. All of the statistical analyses were carried out with the statistical software package SPSS 21.0 (IBM, Corps.). Data are presented as mean \pm standard error of the mean. The $\chi^{2}$ test and Fisher's exact test were used to analyze the relationship between MYH9 protein expression levels and clinicopathological characteristics. Patient survival was determined by a Kaplan-Meier analysis and the differences were counted by the log-rank test. Cox's proportional hazards regression model was applied to the multivariate analysis. $\mathrm{P}<0.05$ was considered to indicate a statistically significant difference.

\section{Results}

MYH9 protein expression is upregulated in EOC. To determine whether MYH9 is a pro-tumor or antitumor gene in ovarian cancer, immunohistochemical analysis was performed in 265 cases of paraffin-embedded epithelial ovarian cancer tissues and 41 cases of ovarian paratumor tissues. Of the 265 evaluable ovarian tumors stained, 72/265 (27.17\%) had weak/absent staining (also called low expression) and 193/265 (72.83\%) had strong/moderate staining (also called high expression). Moreover, of the 41 ovarian paratumor tissues stained, 30/41 (73.17\%) had weak/absent staining (also called low expression) and only 11/41 (26.83\%) had strong/moderate staining (also called high expression), and there was significantly different staining between low and high MYH9 expression groups ( $\mathrm{P}<0.001$; Fig. 1A). In addition, it was demonstrated that MYH9 expression staining located in the cytoplasm (Fig. 1B).

MYH9 overexpression is associated with disease progression free and overall survival in ovarian cancer patients. To determine whether the MYH9 expression was associated with ovarian cancer patient's survival, in the present study 265 cases of EOC were stained using immunohistochemistry with a specific MYH9 antibody. Kaplan-Meier survival analysis demonstrated that there was a significant difference in disease 


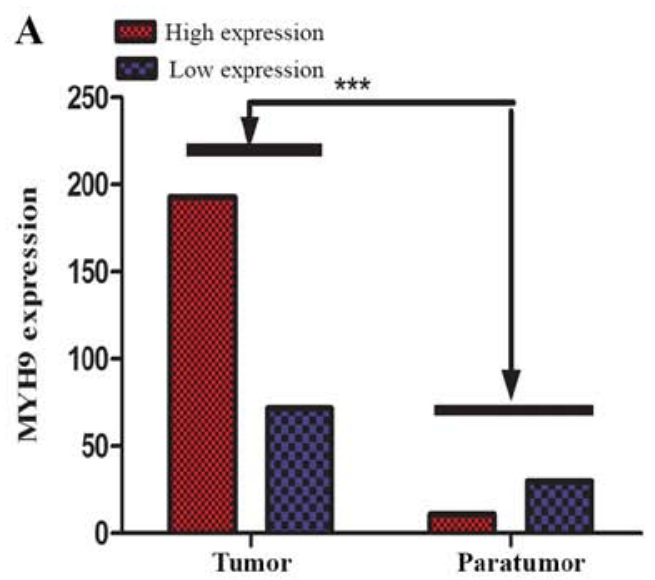

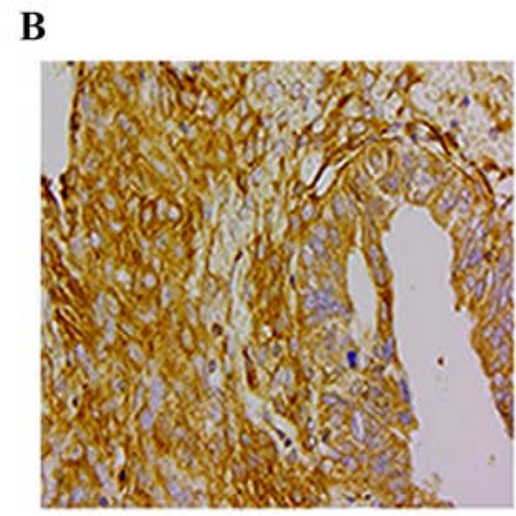

Tumor

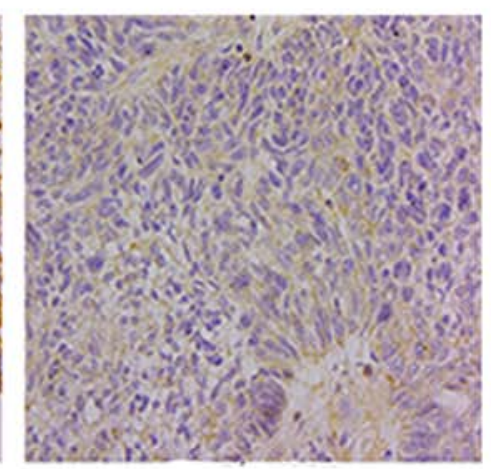

Paratumor

Figure 1. MYH9 expression in epithelial ovarian cancer tissues with immunohistochemistry. (A) MYH9 expression was upregulated in epithelial ovarian cancer tissues. ${ }^{* * *} \mathrm{P}<0.0001$. (B) MYH9 expression staining located at cytoplasmic in ovarian cancer tissue and paratumor tissue. MYH9, myosin 9.
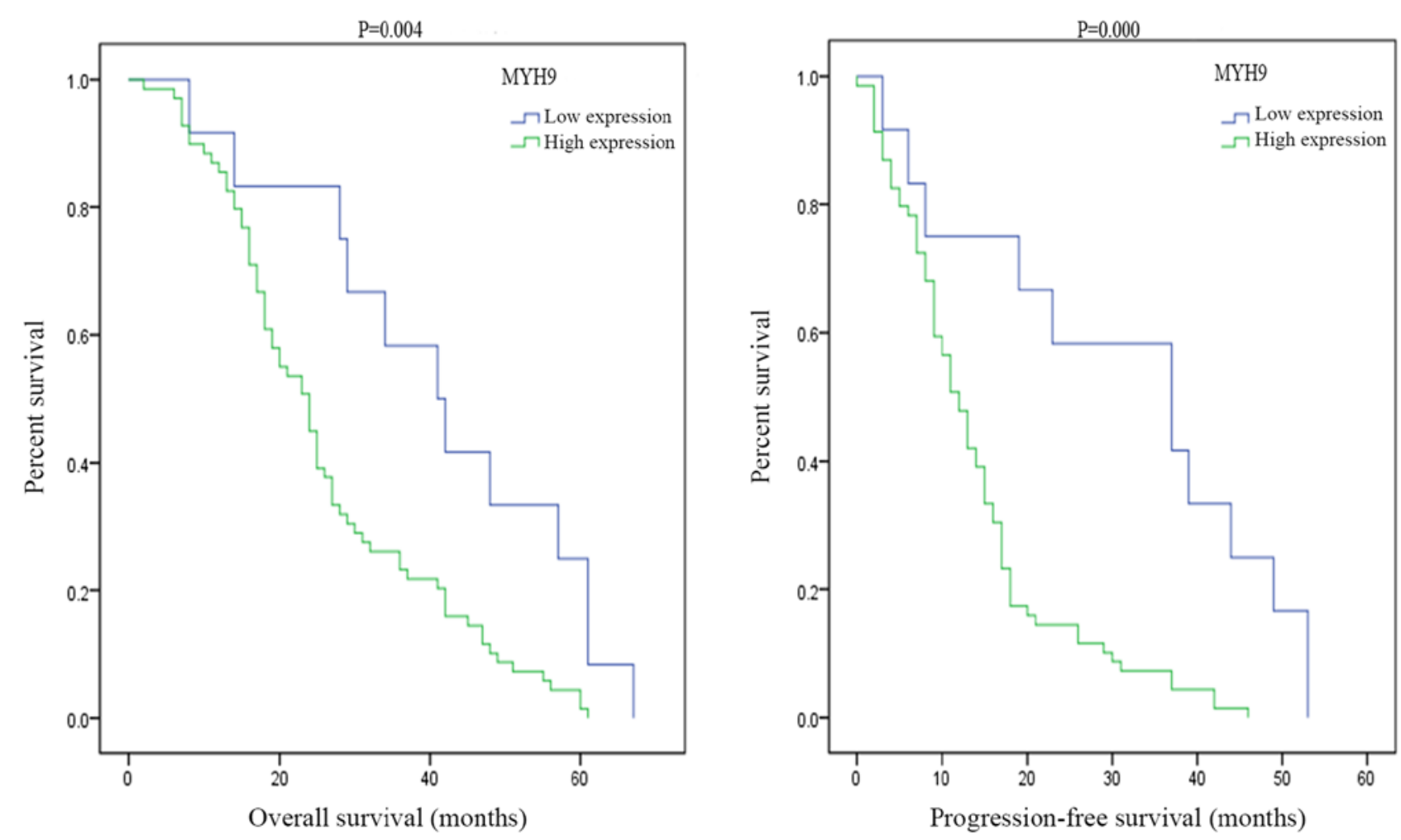

Figure 2. MYH9 overexpression was associated with disease progression free and overall survival in ovarian cancer patients. MYH9, myosin 9.

progression free survival between high and low expression of MYH9 ( $\mathrm{P}=0.004$; Fig. 2). Moreover, there was also a statistically significance on overall survival between high and low MYH9 expression (Fig. 2). A survival analysis plot revealed that the cumulative overall survival (OS) and disease progression free survival (PFS) rates of ovarian cancer patients decreased with increasing MYH9 protein expression. In this study, patients with high expression of MYH9 exhibited a median overall survival time of 24 months, while patients with low expression of MYH9 exhibited a median overall survival time of 41 months. Moreover, patients with MYH9 high expression exhibited a median disease progression free survival time of 12 months, while patients with MYH9 low expression exhibited a median disease progression free survival time of 37 months.
Representative photomicrographs of the EOC tissues immunohistochemically stained for MYH9. In 265 cases of ovarian cancer tissues stained with the MYH9 specific antibody, 22 cases had no staining, 50 cases had weak staining, 117 cases had moderate staining and 76 cases had strong staining (Fig. 3). MYH9 expression is located at the cytoplasm and no expression at the nucleus.

The association between MYH9 expression and clinicopathological variables. From Table I, it was demonstrated that the percentages of patients with stages I, II, III and IV tumors were $16.23,10.19,58.87$, and $14.71 \%$, respectively, which demonstrated that most of epithelial ovarian cancer was diagnosed at an advanced stage. In addition, most of histological type is 

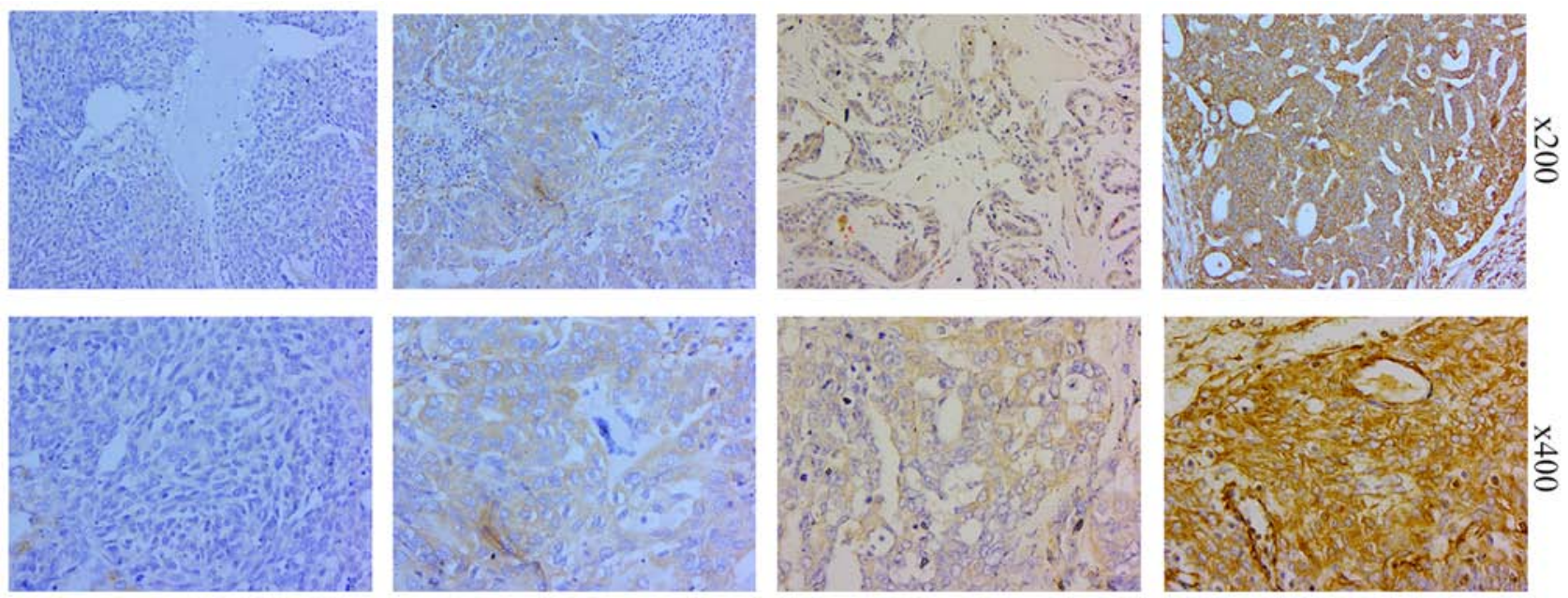

Figure 3. Representative photomicrographs (x200 and x400) of the epithelial ovarian cancer tissues immunohistochemically stained for myosin 9.

serous adenocarcinoma (69.87\% in the present study). In addition, The results of the statistical analysis using $\chi^{2}$ or Fisher's Exact test demonstrated a significant relationship between MYH9 expression and clinicopathological characteristics of EOC, such as the following factors: FIGO stage, lymph node metastasis, intraperitoneal metastasis, vital status (at last follow-up), intraperitoneal recurrence, residual tumor size, and ascites with tumor cells $(\mathrm{P}<0.05$; Table I). Moreover, there were no significance in the following factors: Age, histological type, intestinal metastasis, distant recurrence, differentiation grade, neoadjuvant chemotherapy, postoperative chemotherapy, platinum resistance, hyperthermic intraperitoneal chemotherapy, cytoreductive surgery, serum CA125, CA72-4, carcinoembryonic antigen, $\alpha$-fetoprotein, CA153 and human epididymis protein 4.

MYH9 overexpression is significantly associated with a poor prognosis. Furthermore, the prognostic value of MYH9 expression in EOC patients were also analyzed. In a univariate Cox analysis, MYH9 expression, intraperitoneal metastasis, intestinal metastasis, postoperative chemotherapy and hyperthermic intraperitoneal chemotherapy were significant prognostic factors $(\mathrm{P}<0.05$; Table II). Moreover, using a multivariate Cox regression analysis found that MYH9 expression, intestinal metastasis, postoperative chemotherapy and hyperthermic intraperitoneal chemotherapy were indeed independent prognostic factors of ovarian cancer (Table II), but intraperitoneal metastasis was no longer significant $(\mathrm{P}=0.570)$. Taken together, these results suggest that MYH9 expression was an independent prognostic factor and MYH9 overexpression may be corelated with the prognosis of epithelial ovarian cancer, which suggested that MYH9 may be a useful independent prognostic marker in EOC.

\section{Discussions}

The MYH9 gene encodes the heavy chain of non-muscle myosin of class II, isoform A (also called NM IIA). MYH9 plays a different role in human cancers (4-15). MYH9 plays an oncogenic role in a number of types of cancers (5-12), such as gastric cancer, colorectal cancer, esophageal squamous cancer, non-small cell lung cancer and breast cancer. However, in contrast, it plays a tumor suppressor in a number of cancers (13-15), such as human skin and head and neck SCCs, tongue SCC and human invasive lobular breast carcinoma. However, there have been no studies about the role of MYH9 in ovarian cancer. In this study the authors for the first time to the best of our knowledge demonstrated that MYH9 protein expression was elevated in EOC tissues and out of 265 evaluable ovarian tumors stained, 72/265 (27.17\%) had weak/absent staining and 193/265 (72.83\%) had strong/moderate staining (also called high expression). However, out of 41 ovarian paratumor tissues stained, 30/41 (73.17\%) had weak/absent staining (also called low expression) and only 11/41 (26.83\%) had strong/moderate staining (also called high expression), which suggested that MYH9 may play an oncogenic role in EOC. As is known, EOC is an adenocarcinoma pathologically and in previous studies MYH9 was demonstrated to play a tumor suppressor role in a number of squamous carcinomas (15-17). The present study demonstrated the same discrepancy as with the previous studies (7-14). In addition, survival analysis revealed that the cumulative OS and PFS rates of EOC patients decreased with increasing MYH9 protein expression, and high expression of MYH9 exhibited a poorer median OS and PFS, which demonstrated that MYH9 overexpression predicts a poor prognosis of EOC.

Moreover, overexpression of MYH9 in EOC patients was found to be associated with the following factors, such as FIGO stage, lymph node metastasis, intraperitoneal metastasis, vital status (at last follow-up), intraperitoneal recurrence, residual tumor size and ascites with tumor cells. In the present study, it was demonstrated that patients with MYH9 overexpression were more frequently in stage III/IV compared with stage I/II, which demonstrated that MYH9 overexpression were more likely to be associated with advanced disease, therefore it was concluded that MYH9 expression increased with the occurrence and progress of ovarian cancer. Moreover, MYH9 overexpression was associated with lymph node metastasis and intraperitoneal metastasis, which demonstrated that high expression of MYH9 was associated with the metastasis of epithelial ovarian cancer. In addition, intraperitoneal recurrence 
Table I. Association between MYH9 expression and clinicopathological variables using the $\chi^{2}$ or Fisher's exact test.

\begin{tabular}{|c|c|c|c|c|c|}
\hline \multirow[b]{2}{*}{ Characteristic } & \multirow[b]{2}{*}{ Total, n (\%) } & \multicolumn{2}{|c|}{ МYH9 } & \multirow[b]{2}{*}{$\begin{array}{c}\chi^{2} \text { test } \\
\text { P-value }\end{array}$} & \multirow[b]{2}{*}{$\begin{array}{l}\text { Fisher's exact } \\
\text { test P-value }\end{array}$} \\
\hline & & $\begin{array}{l}\text { No or low } \\
\text { expression }\end{array}$ & $\begin{array}{c}\text { Moderate or } \\
\text { strong expression }\end{array}$ & & \\
\hline \multicolumn{6}{|l|}{ Age, years } \\
\hline$\leq 50$ & $122(46.04)$ & 39 & 83 & 0.1049 & \\
\hline$>50$ & $143(53.96)$ & 33 & 110 & & \\
\hline \multicolumn{6}{|l|}{ Histological type } \\
\hline Serous adenocarcinoma & $160(69.87)$ & 38 & 122 & 0.0684 & \\
\hline Mucoid adenocarcinoma & $13 \quad(5.68)$ & 5 & 8 & & \\
\hline Endometrial adenocarcinoma & $38(16.59)$ & 13 & 25 & & \\
\hline Clear cell carcinoma & $18(7.86)$ & 9 & 9 & & \\
\hline \multicolumn{6}{|l|}{ FIGO stage } \\
\hline $\mathrm{I}$ & $43(16.23)$ & 17 & 26 & 0.0011 & \\
\hline II & $27(10.19)$ & 14 & 13 & & \\
\hline III & $156(58.87)$ & 35 & 121 & & \\
\hline IV & $39(14.71)$ & 6 & 33 & & \\
\hline \multicolumn{6}{|l|}{ Lymph node metastasis } \\
\hline No & $61(58.10)$ & 30 & 31 & 0.0059 & \\
\hline Yes & $44(41.90)$ & 10 & 34 & & \\
\hline \multicolumn{6}{|l|}{ Intraperitoneal metastasis } \\
\hline No & $87(32.95)$ & 39 & 48 & $<0.0001$ & \\
\hline Yes & $177(67.05)$ & 33 & 144 & & \\
\hline \multicolumn{6}{|l|}{ Intestinal metastasis } \\
\hline No & $135(51.14)$ & 39 & 96 & 0.5464 & \\
\hline Yes & $129(48.86)$ & 33 & 96 & & \\
\hline \multicolumn{6}{|l|}{ Vital status } \\
\hline Alive & $111(57.81)$ & 46 & 65 & $<0.0001$ & \\
\hline Dead & $81(42.19)$ & 12 & 69 & & \\
\hline \multicolumn{6}{|l|}{ Intraperitoneal recurrence } \\
\hline No & $186(71.81)$ & 60 & 126 & 0.0053 & \\
\hline Yes & $73(28.19)$ & 11 & 62 & & \\
\hline \multicolumn{6}{|l|}{ Distant recurrence } \\
\hline No & $222(85.71)$ & 64 & 158 & 0.2109 & \\
\hline Yes & $37(14.29)$ & 7 & 30 & & \\
\hline \multicolumn{6}{|l|}{ Residual tumor size (cm) } \\
\hline$\leq 1$ & $241(90.94)$ & 70 & 171 & 0.0296 & 0.0302 \\
\hline$>1$ & $24(9.06)$ & 2 & 22 & & \\
\hline \multicolumn{6}{|l|}{ Differentiation grade } \\
\hline $\mathrm{G} 1 / \mathrm{G} 2$ & $96(39.51)$ & 28 & 68 & 0.4184 & \\
\hline $\mathrm{G} 3$ & $147(60.49)$ & 36 & 111 & & \\
\hline \multicolumn{6}{|l|}{ Neoadjuvant chemotherapy } \\
\hline No & $234(88.30)$ & 67 & 167 & 0.1414 & 0.1967 \\
\hline Yes & $31(11.70)$ & 5 & 26 & & \\
\hline \multicolumn{6}{|l|}{ Postoperative chemotherapy } \\
\hline No & $8(3.05)$ & 1 & 7 & & 0.4520 \\
\hline Yes & $254(96.95)$ & 71 & 183 & & \\
\hline \multicolumn{6}{|l|}{ Platinum resistance } \\
\hline No & $255(97.33)$ & 70 & 185 & & $>0.05$ \\
\hline Yes & $7 \quad(2.67)$ & 2 & 5 & & \\
\hline
\end{tabular}


Table I. Continued.

\begin{tabular}{|c|c|c|c|c|c|}
\hline \multirow[b]{2}{*}{ Characteristic } & \multirow[b]{2}{*}{ Total, $\mathrm{n}(\%)$} & \multicolumn{2}{|c|}{ МYH9 } & \multirow[b]{2}{*}{$\begin{array}{l}\chi^{2} \text { test } \\
\text { P-value }\end{array}$} & \multirow[b]{2}{*}{$\begin{array}{c}\text { Fisher's exact } \\
\text { test P-value }\end{array}$} \\
\hline & & $\begin{array}{l}\text { No or low } \\
\text { expression }\end{array}$ & $\begin{array}{c}\text { Moderate or } \\
\text { strong expression }\end{array}$ & & \\
\hline \multicolumn{6}{|c|}{ Hyperthermic intraperitoneal chemotherapy } \\
\hline No & $240(90.91)$ & 65 & 175 & 0.8270 & \\
\hline Yes & $24 \quad(9.09)$ & 7 & 17 & & \\
\hline \multicolumn{6}{|c|}{ Ascites with tumor cells (+) } \\
\hline No & $56(50.91)$ & 24 & 32 & 0.0058 & \\
\hline Yes & $54(49.09)$ & 10 & 44 & & \\
\hline \multicolumn{6}{|c|}{ Cytoreductive surgery } \\
\hline No & $9(3.42)$ & 1 & 8 & 0.2655 & 0.4515 \\
\hline Yes & $254(96.58)$ & 71 & 183 & & \\
\hline \multicolumn{6}{|l|}{ CA125 (U/ml) } \\
\hline$\leq 35$ & $32(12.65)$ & 11 & 21 & 0.3060 & \\
\hline$>35$ & $221(87.35)$ & 57 & 164 & & \\
\hline \multicolumn{6}{|l|}{ CA72-4 (U/ml) } \\
\hline$\leq 7$ & $99(45.83)$ & 30 & 69 & 0.4459 & \\
\hline$>7$ & $117(54.17)$ & 30 & 87 & & \\
\hline \multicolumn{6}{|l|}{ CA153 (U/ml) } \\
\hline$\leq 25$ & $31(32.29)$ & 6 & 25 & 0.5664 & \\
\hline$>25$ & $65(67.71)$ & 16 & 49 & & \\
\hline \multicolumn{6}{|l|}{$\operatorname{AFP}(\mathrm{U} / \mathrm{ml})$} \\
\hline$\leq 25$ & $209(99.05)$ & 59 & 150 & & $>0.05$ \\
\hline$>25$ & $2(0.95)$ & 0 & 2 & & \\
\hline \multicolumn{6}{|l|}{ CEA (U/ml) } \\
\hline$\leq 5.0$ & $189(88.32)$ & 54 & 135 & 0.9526 & \\
\hline$>5.0$ & $25(11.68)$ & 7 & 18 & & \\
\hline \multicolumn{6}{|l|}{ HE4 (pmol/l) } \\
\hline$\leq 140$ & $45(34.35)$ & 16 & 29 & 0.6301 & \\
\hline$>140$ & $86(65.65)$ & 27 & 59 & & \\
\hline
\end{tabular}

MYH9, myosin 9; FIGO, International Federation of Gynecology and Obstetrics. AFP, $\alpha$-fetoprotein; CEA, carcinoembryonic antigen; HE4, human epididymis protein 4.

occurred more frequently in the MYH9 high expression group, which showed that MYH9 overexpression was associated with the recurrence of EOC. As far as the authors know, EOC metastasis and recurrence are the major mortality factors, and patients with metastasis and recurrence usually have a shorter life span. Therefore, early diagnosis of metastasis and recurrence is important for prolonging the survival of ovarian cancer patients, however there are few tumor markers for predicting metastasis and recurrence of ovarian cancer in the clinic. According to the results of the present study, MYH9 overexpression was associated with lymph node metastasis, intraperitoneal metastasis and recurrence, and is meaningful as a biomarker or predictor to diagnose lymph node metastasis, intraperitoneal metastasis and recurrence. All of these results suggested that MYH9 overexpression is associated with a poor prognosis of EOC and it could be recommended as a candidate molecular biomarker of EOC. Moreover, it was concluded that MYH9 may directly or indirectly participate in the migration and invasion of ovarian cancer. However, more in vivo and in vitro experiments are required to identify its role in EOC.

Furthermore, using univariate Cox analysis it was found that MYH9 expression, intraperitoneal metastasis, intestinal metastasis, postoperative chemotherapy and hyperthermic intraperitoneal chemotherapy were prognostic factors. In addition, in a multivariate Cox regression analysis demonstrated that MYH9 expression, intestinal metastasis, postoperative chemotherapy and hyperthermic intraperitoneal chemotherapy were independent prognostic factors of ovarian cancer, but intraperitoneal metastasis was not significantly associated. All these results suggest that MYH9 expression is an independent prognostic factor and MYH9 overexpression may be corelated 
Table II. Cox regression univariate and multivariate analyses of prognostic factors in epithelial ovarian cancer.

\begin{tabular}{|c|c|c|c|c|c|}
\hline \multirow[b]{2}{*}{ Variable } & \multicolumn{3}{|c|}{ Univariate analysis } & \multicolumn{2}{|c|}{ Multivariate analysis } \\
\hline & $\begin{array}{l}\text { Number } \\
\text { of patients }\end{array}$ & P-value & $\begin{array}{c}\text { Regression } \\
\text { coefficient (SE) }\end{array}$ & P-value & $\begin{array}{c}95 \% \text { confidence } \\
\text { interval }\end{array}$ \\
\hline \multicolumn{6}{|l|}{ MYH9 } \\
\hline Low expression & 72 & 0.007 & 0.339 & 0.009 & $1.250-4.802$ \\
\hline High expression & 193 & & & & \\
\hline \multicolumn{6}{|c|}{ Intraperitoneal metastasis } \\
\hline No & 87 & 0.026 & 0.320 & 0.570 & - \\
\hline Yes & 177 & & & & \\
\hline \multicolumn{6}{|c|}{ Intestinal metastasis } \\
\hline No & 135 & 0.040 & 0.250 & 0.011 & $1.176-3.422$ \\
\hline Yes & 129 & & & & \\
\hline \multicolumn{6}{|c|}{ Postoperative chemotherapy } \\
\hline No & 8 & 0.004 & 0.639 & $<0.001$ & $0.024-0.347$ \\
\hline Yes & 254 & & & & \\
\hline \multicolumn{6}{|c|}{ Hyperthermic intraperitoneal chemotherapy } \\
\hline No & 240 & 0.007 & 0.485 & 0.026 & $1.138-7.935$ \\
\hline Yes & 24 & & & & \\
\hline
\end{tabular}

MYH9, myosin 9; SE, standard error.

with the prognosis of EOC, which suggested that MYH9 may be a useful independent prognostic marker in EOC. In addition, intraperitoneal metastasis and intestinal metastasis were associated with poor prognosis of EOC, so more efficacious treatment methods should be given to these patients. Moreover, the present study suggested that hyperthermic intraperitoneal chemotherapy should be performed in cytoreductive surgery, because it influences the prognosis of EOC.

In conclusion, MYH9 overexpression was associated with FIGO stage, lymph node metastasis, intraperitoneal metastasis, vital status, intraperitoneal recurrence, residual tumor size and ascites with tumor cells. Additionally, it was an independent prognostic factor and its overexpression may be associated with the poor prognosis of ovarian cancer. Furthermore, MYH9 can be recommended as a useful independent prognostic marker in EOC. In future, more in vivo and in vitro studies are required to demonstrate its role and molecular mechanism in development and progression of ovarian cancer.

\section{Acknowledgements}

The authors would like to thank Professor Zhongqiu Lin for providing ovarian cancer and paratumor paraffin-embedded tissues.

\section{Funding}

The present study was supported by the Nature Science Fund of Guangdong Province (grant no. 2016A030313536) and the Guangdong Provincial Medical Research Fund (grant no. A2019096).

\section{Availability of data and materials}

All data generated or analyzed during this study are included in this published article.

\section{Authors' contributions}

$\mathrm{ZZ}$ conceived and designed the experiments. LL and JJY performed the experiments. XD, JHY and BZ analyzed the data. ZL was involved in preparing paraffin-embedded ovarian cancer tissue samples. LL wrote the paper. All authors have read and approved the final manuscript.

\section{Ethics approval and consent to participate}

The Ethics Committee of the Memorial Hospital of Sun Yat-sen University authorized the experimental and research protocols of this study. All procedures performed in studies were in accordance with the ethical standards of the institutional and/or national research committee and with the 1964 Helsinki declaration and its later amendments or comparable ethical standards. All controls and patients (or relatives of patients who already died) provided written informed consent.

\section{Patient consent for publication}

Not applicable.

\section{Competing interests}

The authors declare that they have no competing interests. 


\section{References}

1. Jemal A, Bray F, Center MM, Ferlay J, Ward E and Forman D: Global cancer statistics. CA Cancer J Clin 61: 69-90, 2011.

2. Weberpals JI, Koti M and Squire JA: Targeting genetic and epigenetic alterations in the treatment of serous ovarian cancer. Cancer Genet 204: 525-535, 2011.

3. Jayson GC, Kohn EC, Kitchener HC and Ledermann JA: Ovarian cancer. Lancet 384: 1376-1388, 2014.

4. Ahmed AA and Abdou AM: Diagnostic accuracy of CA125 and HE4 in ovarian carcinoma patients and the effect of confounders on their serum levels. Curr Probl Cancer: S0147-0272(18)30164-8, 2019.

5. Dochez V, Caillon H, Vaucel E, Dimet J, Winer $\mathrm{N}$ and Ducarme G: Biomarkers and algorithms for diagnosis of ovarian cancer: CA125, HE4, RMI and ROMA, a review. J Ovarian Res 12: 28, 2019.

6. Pecci A, Ma X, Savoia A and Adelstein RS: MYH9: Structure, functions and role of non-muscle myosin IIA in human disease. Gene 664: 152-167, 2018.

7. Liang S, He L, Zhao X, Miao Y, Gu Y, Guo C, Xue Z, Dou W, $\mathrm{Hu} \mathrm{F}, \mathrm{Wu} \mathrm{K}$, et al: MicroRNA let-7f inhibits tumor invasion and metastasis by targeting MYH9 in human gastric cancer. PLoS One 6: e18409, 2011.

8. Park SY, Kim H, Yoon S, Bae JA, Choi SY, Jung YD and Kim KK: KITENIN-targeting microRNA-124 suppresses colorectal cancer cell motility and tumorigenesis. Mol Ther 22: 1653-1664, 2014.

9. Xia ZK, Yuan YC, Yin N, Yin BL, Tan ZP and Hu YR: Nonmuscle myosin IIA is associated with poor prognosis of esophageal squamous cancer. Dis Esophagus 25: 427-436, 2012.

10. Hosono Y, Usukura J, Yamaguchi T, Yanagisawa K, Suzuki M and Takahashi T: MYBPH inhibits NM IIA assembly via direct interaction with NMHC IIA and reduces cell motility. Biochem Biophys Res Commun 428: 173-178, 2012.

11. Katono K, Sato Y, Jiang SX, Kobayashi M, Nagashio R, Ryuge S, Fukuda E, Goshima N, Satoh Y, Saegusa M and Masuda N: Prognostic significance of MYH9 expression in resected non-small cell lung cancer. PLoS One 10: e0121460, 2015.

12. Derycke L, Stove C, Vercoutter-Edouart AS, De Wever O, Dollé L, Colpaert N, Depypere H, Michalski JC and Bracke M: The role of non-muscle myosin IIA in aggregation and invasion of human MCF-7 breast cancer cells. Int J Dev Biol 55: 835-840, 2011.
13. Liao Q, Li R, Zhou R, Pan Z, Xu L, Ding Y and Zhao L: LIM kinase 1 interacts with myosin-9 and alpha-actinin-4 and promotescolorectal cancer progression. Br J Cancer 117: 563-571, 2017.

14. Ye G, Huang K, Yu J, Zhao L, Zhu X, Yang Q, Li W, Jiang Y, Zhuang B, Liu H, et al: MicroRNA-647 targets SRF-MYH9 axis to suppress invasion and metastasis of gastric cancer. Theranostics 7: 3338-3353, 2017.

15. Schramek D, Sendoel A, Segal JP, Beronja S, Heller E, Oristian D, Reva B and Fuchs E: Direct in vivo RNAi screen unveils myosin IIa as a tumor suppressor of squamous cell carcinomas. Science 343: 309-313, 2014

16. Coaxum SD, Tiedeken J, Garrett-Mayer E, Myers J, Rosenzweig SA and Neskey DM: The tumor suppressor capability of p53 is dependent on non-muscle myosin IIA function in head and neck cancer. Oncotarget 8: 22991-23007, 2017.

17. Wei XH, Lin SS, Liu Y, Zhao RP, Khan GJ, Du HZ, Mao TT, Yu BY, Li RM, Yuan ST and Sun L: DT-13 attenuates human lung cancer metastasis via regulating NMIIA activity under hypoxia condition. Oncol Rep 36: 991-999, 2016.

18. Conti MA, Saleh AD, Brinster LR, Cheng H, Chen Z, Cornelius S, Liu C, Ma X, Van Waes C and Adelstein RS: Conditional deletion of nonmuscle myosin II-A in mouse tongue epithelium results in squamous cell carcinoma. Sci Rep 5: 14068, 2015.

19. Kas SM, de Ruiter JR, Schipper K, Annunziato S, Schut E, Klarenbeek S, Drenth AP, van der Burg E, Klijn C, Ten Hoeve JJ, et al: Insertional mutagenesis identifies drivers of a novel oncogenic pathway in invasive lobular breast carcinoma. Nat Genet 49: 1219-1230, 2017.

20. Liu L, Zeng Z, Yi J, Zuo L, Lv J, Yuan J, Lin Z, Luo R and Feng X: Expression and clinical significance of transcription factor 4 (TCF4) in epithelial ovarian cancer. Cancer Biomark. 24: 213-221, 2019.

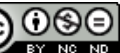

This work is licensed under a Creative Commons Attribution-NonCommercial-NoDerivatives 4.0 International (CC BY-NC-ND 4.0) License. 